\title{
Immobilization of Clover-trapped White-tailed Deer, Odocoileus virginianus, with Medetomidine and Ketamine, and Antagonism with Atipamezole
}

\author{
Joshua J. Millspaugh ${ }^{1}$, Brian E. Washburn ${ }^{1}$, Tamara M. Meyer ${ }^{2}$, Jeff Beringer ${ }^{2}$, and Lonnie P. \\ HANSEN $^{2}$
}

${ }^{1}$ Department of Fisheries and Wildlife Sciences, University of Missouri, 302 Anheuser-Busch Natural Resources Building, Columbia, Missouri 65211 USA

${ }^{2}$ Missouri Department of Conservation, Conservation Research Center, 1110 South College Avenue, Columbia, Missouri 65201 USA

Millspaugh, Joshua J., Brian E. Washburn, Tamara M. Meyer, Jeff Beringer, and Lonnie P. Hansen. 2004. Immobilization of Clover-trapped White-tailed Deer, Odocoileus virginianus, with medetomidine and ketamine, and antagonism with atipamezole. Canadian Field-Naturalist 118(2): 185-190.

We evaluated the effectiveness of immobilizing Clover-trapped White-tailed Deer (Odocoileus virginanus) with medetomidine hydrochloride $(\mathrm{HCl})$ and ketamine $\mathrm{HCl}$ during winter and summer by monitoring immobilization intervals and vital signs. In winter, we captured deer in Clover traps in 1 4-ha research enclosure for relocation to another on-site enclosure $(n=5)$. In summer, we captured free-ranging deer in Clover traps to attach radio-collars $(n=4)$. We administered an estimated 0.055 $\mathrm{mg} / \mathrm{kg}$ medetomidine $\mathrm{HCl}$ and $2.5 \mathrm{mg} / \mathrm{kg}$ ketamine $\mathrm{HCl}$ to adult $(>1.5$ years of age) deer and $0.06 \mathrm{mg} / \mathrm{kg}$ medetomidine $\mathrm{HCl}$ and $2.5 \mathrm{mg} / \mathrm{kg}$ ketamine $\mathrm{HCl}$ to subadult $(<1.5$ years of age $)$ deer. We used an intramuscular injection of atipamezole $\mathrm{HCl}$ as the antagonist at a rate of $0.275 \mathrm{mg} / \mathrm{kg}$ for adults and $0.3 \mathrm{mg} / \mathrm{kg}$ for subadults $>30$ minutes post-induction. Mean induction time in winter was 11.2 minutes $(\mathrm{SE}=2.5$, range $=5.4-24.2)$ and 6.5 minutes $(\mathrm{SE}=0.8$, range $=6.2-7.5)$ in summer. After atipamezole $\mathrm{HCl}$ injection, the mean time to walking was 17.1 minutes $(\mathrm{SE}=3.5$, range $=7.5-41.5$ minutes $)$ in winter and 11.3 minutes $(\mathrm{SE}=3.8$, range $=4.7-13.5)$ in summer. Rectal temperature was relatively constant throughout immobilization; however rectal temperatures of 5 deer ( $n=3$ in winter; $n=2$ in summer) exceeded $40^{\circ} \mathrm{C}$, a sign of hyperthermia. Respiration rate and pulse rate peaked at about 20 minutes post-medetomidine $\mathrm{HCl}$ and ketamine $\mathrm{HCl}$ injection, then generally declined thereafter. No mortalities were observed in our study. Medetomidine $\mathrm{HCl}$ and ketamine $\mathrm{HCl}$ doses for Clover-trapped White-tailed Deer provided satisfactory induction times, sufficient level of anesthesia for short-distance relocation or radio-collar attachment, and were effectively reversed with an IM injection of atipamezole $\mathrm{HCl}$.

Key words: White-tailed Deer, Odocoileus virginianus, atipamezole, capture, chemical restraint, Clover trap, deer, ketamine, immobilization, medetomidine, Missouri.

White-tailed Deer (Odocoileus virginianus) have been chemically immobilized with Telazol ${ }^{\circledR}(1: 1$ tiletamine hydrochloride $(\mathrm{HCl})$ and zolazepam $\mathrm{HCl})$ and xylazine $\mathrm{HCl}$ (Schultz et al. 1992; Kilpatrick and Spohr 1999), ketamine $\mathrm{HCl}$ and xylazine $\mathrm{HCl}$ (Mech et al. 1985; Farley et al. 1986; Kreeger et al. 1986; Ballard et al. 1998; Kilpatrick and Spohr 1999), etorphine and xylazine $\mathrm{HCl}$ (Presnell et al. 1973; Presidente et al. 1973; Nielsen 1982), xylazine $\mathrm{HCl}$ alone (Gibson et al. 1982), phencyclidine $\mathrm{HCl}$ (Dean et al. 1973), and succinylcholine chloride (Wesson et al. 1974; Jacobsen et al. 1976). Kreeger (1996) recommended $4.4 \mathrm{mg} / \mathrm{kg}$ Telazol ${ }^{\circledR}$ and $2.2 \mathrm{mg} / \mathrm{kg}$ xylazine $\mathrm{HCl}$ to immobilize White-tailed Deer; $0.125 \mathrm{mg} / \mathrm{kg}$ yohimbine $\mathrm{HCl}$ was the recommended antagonist. Recently, Kilpatrick and Spohr (1999) used a 4.8:3.9 mg/kg dose of Telazol ${ }^{\circledR}$ : xylazine $\mathrm{HCl}$ to dart free-ranging White-tailed Deer. Alternative drugs recommended by Kreeger (1996) include ketamine $\mathrm{HCl}$ and xylazine $\mathrm{HCl}$, etorphine, xylazine alone (for calm deer only), and a combination of medetomidine $\mathrm{HCl}$ and ketamine $\mathrm{HCl}$.

Medetomidine $\mathrm{HCl}$ depresses the central nervous system and acts similarly to xylazine $\mathrm{HCl}$ (Jalanka and
Roeken 1990), but with greater affinity to alpha adrenoreceptors (Klein and Klide 1989; Jalanka and Roeken 1990; Kreeger 1996). Ketamine HCl, an anesthetic, is often combined with a tranquilizer or sedative to improve induction and recovery (Haigh 1982; Kreeger 1996). Medetomidine $\mathrm{HCl}$ and ketamine $\mathrm{HCl}$ alone or in combination with other drugs have been successfully used to immobilize a diversity of large ungulates including Reindeer (Rangifer tarandus tarandus) (Ryeng et al. 2001, 2002), Mule Deer (Odocoileus hemionus) (Caulkett et al. 2000), Mule Deer/Whitetailed Deer hybrids (Caulkett et al. 2000), Sika Deer (Cervus nippon) (Tsuruga et al. 1999), gemsbok (Oryx gazella) (Grobler et al. 2001), Roan Antelope (Hippotragus equinus) (Citino et al. 2001), Blue Duiker (Cephalophus monticola) (Bailey et al. 1995), Moose (Alces alces) (Arnemo 1995), Tigers (Panthera tigris) (Miller et al. 2003), Impala (Aepyceros melampus) (Bush et al. 2004), European Mink (Mustela lutreola) Fournier-Chambrillon et al. 2003) and Red Deer (Cervus elaphus) (Arnemo et al. 1994).

Notable among the advantages listed in these and other studies is the ability to reverse medetomidine $\mathrm{HCl}$ 
with an intramuscular (IM) injection of atipamezole $\mathrm{HCl}$ (Tsuruga et al. 1999; Haulena et al. 2000). Atipamezole $\mathrm{HCl}$ is an extremely efficient alpha ${ }_{2}$-adrenergic antagonist compared with yohimbine $\mathrm{HCl}$ and tolazoline $\mathrm{HCl}$ (Kreeger 1996) and effectively reverses medetomidine $\mathrm{HCl}$ in many wildlife species (Tsuruga et al. 1999; Haulena et al. 2000; Grobler et al. 2001). If medetomidine $\mathrm{HCl}$ and ketamine $\mathrm{HCl}$ were as efficient and safe as other immobilizing agents (e.g., Tela$\mathrm{zol}^{\circledR}$ and xylazine $\mathrm{HCl}$ ) and if an IM injection of atipamezole $\mathrm{HCl}$ was a safe and effective antagonist, this combination could prove efficacious in field studies. Our objective was to determine the effectiveness and safety of immobilizing Clover-trapped White-tailed Deer with medetomidine $\mathrm{HCl}$ and ketamine $\mathrm{HCl}$, and the feasibility of reversing this combination with an IM injection of atipamezole $\mathrm{HCl}$, during winter and summer by monitoring immobilization intervals and vital signs. To our knowledge, an evaluation using medetomidine $\mathrm{HCl}$ and ketamine $\mathrm{HCl}$ to immobilize freeranging White-tailed Deer and antagonism by atipamezole $\mathrm{HCl}$ has not been previously published.

\section{Methods}

Our review of the medetomidine $\mathrm{HCl}$ and ketamine $\mathrm{HCl}$ combination took place in winter and summer 2001. In summer and winter, we trapped White-tailed Deer in Clover traps (McCullough 1975). During winter we trapped deer at the Charles W. Green Conservation Area, located near Ashland, Missouri. Traps were baited with corn, set each evening, and checked at sunrise. All winter-trapped and immobilized deer $(n=5)$ were captured within a 4-ha research enclosure for relocation to another on-site 4-ha enclosure. These deer were not habituated to humans.

In summer, we trapped White-tailed Deer at the Thomas S. Baskett Wildlife Research and Education Area, located near Ashland, Missouri. Traps, baited with salt, alfalfa, and corn, were set each evening and checked at sunrise. We captured and immobilized summer-trapped deer $(n=4)$ for purposes of radiocollar attachment. These deer were free-ranging animals and not habituated to humans.

In winter and summer, we immobilized adult deer ( $>1.5$ years of age) ( $n=2$ in winter; $n=3$ in summer) using an estimated $0.055 \mathrm{mg} / \mathrm{kg}$ medetomidine $\mathrm{HCl}$ and $2.5 \mathrm{mg} / \mathrm{kg}$ ketamine $\mathrm{HCl} ; 0.06 \mathrm{mg} / \mathrm{kg}$ medetomidine $\mathrm{HCl}$ and $2.5 \mathrm{mg} / \mathrm{kg}$ ketamine $\mathrm{HCl}$ was administered to subadult deer $(<1.5$ years of age $)(n=3$ in winter; $n=1$ in summer). Adult deer, estimated to be $60 \mathrm{~kg}$, were given $3.3 \mathrm{mg}$ of $1 \mathrm{mg} / \mathrm{ml}$ Domitor $^{\circledR}$ (medetomidine $\mathrm{HCl}$; Orion Corporation, OrionFarmos, Espoo, Finland) and $150 \mathrm{mg}$ of $100 \mathrm{mg} / \mathrm{ml}$ Ketaset $^{\circledR}$ (ketamine $\mathrm{HCl}$; Fort Dodge Laboratories, Inc., Fort Dodge, Iowa, USA). Subadult deer, estimated to be $30 \mathrm{~kg}$, were given $1.8 \mathrm{mg}$ of $1 \mathrm{mg} / \mathrm{ml} \mathrm{mede-}$ tomidine $\mathrm{HCl}$ and $75 \mathrm{mg}$ of $100 \mathrm{mg} / \mathrm{ml}$ ketamine $\mathrm{HCl}$. We injected drugs IM into the biceps femoris with a hand syringe. Sex and age (adult or subadult) were recorded and during winter each deer was marked with a plastic cattle ear tag in one ear for later identification. In summer, deer were fitted with radio-transmitters.

Following sedation in winter and summer, we applied an ophthalmic ointment and blindfolded the deer. In winter, we relocated deer to a different on-site 4-ha enclosure. Two or three field assistants placed the sedated deer into the rear of a vehicle (range from 100 to $300 \mathrm{~m}$ away), which was driven to the release enclosure $(<1 \mathrm{~km}$ driving distance). Each deer was carried into the enclosure $(<30 \mathrm{~m}$ away), and placed in a sternal recumbent position.

We reversed the medetomidine $\mathrm{HCl}$ and ketamine $\mathrm{HCl}$ combination with an IM injection of Antisedan ${ }^{\circledR}$ (atipamezole $\mathrm{HCl}$; Orion Corporation, Orion-Farmos, Espoo, Finland) into the biceps femoris with a hand syringe at a rate of $0.275 \mathrm{mg} / \mathrm{kg}(16.5 \mathrm{mg}$ of $5 \mathrm{mg} / \mathrm{ml}$ atipamezole $\mathrm{HCl})$ for adults and $0.3 \mathrm{mg} / \mathrm{kg}(9 \mathrm{mg}$ of $5 \mathrm{mg} / \mathrm{ml}$ atipamezole $\mathrm{HCl}$ ) for subadults. We visually monitored all deer until they departed the area.

During winter and summer, we attempted to monitor immobilization intervals and vital signs at 5-minute intervals. For all deer, we recorded time of medetomidine $\mathrm{HCl}$ and ketamine $\mathrm{HCl}$ injection, induction (time from injection to time animal was handled), atipamezole $\mathrm{HCl}$ administration, "head up" (time when the animal first lifted its head), "standing" (time when the animal first stood up), and "walking" (time when the animal successfully departed the area). We also recorded respiration rate (breaths/minute), rectal temperature $\left({ }^{\circ} \mathrm{C}\right)$, and pulse rate (beats/minute) at 5 -minute intervals beginning at the time of medetomidine $\mathrm{HCl}$ and ketamine $\mathrm{HCl}$ injection for respiration rate and beginning 10 minutes post-medetomidine $\mathrm{HCl}$ and ketamine $\mathrm{HCl}$ injection for temperature and heart rate.

\section{Results}

Nine deer ( $n=5$ in winter, including 2 female subadults, 1 male subadult, 1 female adult, and 1 male adult; $n=4$ in summer, including 3 adult females and 1 female subadult) were immobilized using the drug combination described above and either relocated or equipped with a radio-collar. No mortality has been observed 10 months post-winter immobilization and 5 months post-summer immobilization.

Mean induction time was 11.2 minutes $(\mathrm{SE}=2.5$, range $=5.4-24.3)$ in winter and 6.5 minutes $(\mathrm{SE}=0.8$, range $=6.2-7.5)$ in summer. Time to atipamezole $\mathrm{HCl}$ injection averaged 54.4 minutes $(\mathrm{SE}=3.7$, range $=37.7$ $-79.2)$ in winter and $33.4(\mathrm{SE}=1.3$, range $=30.4-$ 33.8) in summer. After atipamezole $\mathrm{HCl}$ injection, the mean time to head up was 11.4 minutes $(\mathrm{SE}=2.9$, range $=4-27.5)$ in winter and 9.3 minutes $(\mathrm{SE}=0.7$, range $=8.4-9.9)$ in summer. Mean time to standing was 15.9 minutes $(\mathrm{SE}=3.6$, range $=4.4-41)$ in winter and 10.5 minutes $(\mathrm{SE}=3.2$, range $=4.7-12.3)$ in summer. The mean time to walking was 17.1 minutes 
$(\mathrm{SE}=3.5$, range $=7.5-41.5$ minutes $)$ in winter and 11.3 minutes $(\mathrm{SE}=3.8$, range $=4.7-13.5)$ in summer.

With the exception of rectal temperatures, other vital signs were considered normal (Table 1). Rectal temperatures were stable from 10 - 30 minutes postmedetomidine $\mathrm{HCl}$ and ketamine $\mathrm{HCl}$ injection in summer and winter (Table 1). Temperatures of 1 subadult female captured in winter were $37.4^{\circ} \mathrm{C}$ and $36.2^{\circ} \mathrm{C}$ at 70 and 110 minutes post-induction, respectively; thus, she was within $1.2^{\circ} \mathrm{C}$ of becoming hypothermic (defined as $<35^{\circ} \mathrm{C}$; Kreeger 1996; DelGuidice et al. 2001). No attempt was made to increase body temperature of this individual prior to antagonism with atipamezole $\mathrm{HCl}$. After atipamezole $\mathrm{HCl}$ administration, it took that individual 41.5 minutes to depart, the maximum time observed in our study. Rectal temperatures of 5 deer ( $n=3$ in winter, $n=2$ in summer) exceeded $40^{\circ} \mathrm{C}$, a sign of hyperthermia. No attempt was made to decrease body temperature of these animals prior to antagonism. Respiration rates showed little variability in summer and winter and were generally in the upper 20's to low 30's (breaths/minute) (Table 1) peaking at about 20 minutes post-medetomidine $\mathrm{HCl}$ and ketamine $\mathrm{HCl}$ injection. Pulse rates peaked about 20 minutes post-medetomidine $\mathrm{HCl}$ and ketamine $\mathrm{HCl}$ injection at 95 beats/minute $(\mathrm{SE}=3.6)$ in winter and 103 beats/minute $(\mathrm{SE}=1.4)$ in summer and declined thereafter to 74 beats/minute ( $\mathrm{SE}=5.6)$ in winter and 88 beats/minute $(\mathrm{SE}=3.1)$ in summer at 30 minutes post-medetomidine $\mathrm{HCl}$ and ketamine $\mathrm{HCl}$ injection (Table 1). No other adverse side effects were noted.

During summer captures, response to IM injection of atipamezole $\mathrm{HCl}$ was predictable, as previously described by Jalanka and Roeken (1990). Within 3 6 minutes of atipamezole $\mathrm{HCl}$ injection, "ear-twitching" occurred, followed by leg extensions after an addi- tional 3- 6 minutes, and "head up" 2 minutes thereafter. Standing followed within another 2 minutes and the animal departed almost immediately with good muscle coordination.

\section{Discussion}

Medetomidine $\mathrm{HCl}$ and ketamine $\mathrm{HCl}$ doses for Clover-trapped deer provided satisfactory induction times, produced a sufficient level of anesthesia for short-distance relocation or radio-collar attachment, and were effectively reversed with an IM injection of atipamezole $\mathrm{HCl}$. Small dosage volume, ease of preparation and predictable responses to sedation and to the antagonist make this combination a useful alternative to drug combinations that may require prolonged recovery.

Medetomidine $\mathrm{HCl}$ and ketamine $\mathrm{HCl}$ provided induction times similar to those reported in other studies and with other drugs. For 13 captive Whitetailed Deer in Minnesota, it took 2 to 35 minutes (median $=8, \mathrm{SE}=1.2$ ) from the time of xylazine $\mathrm{HCl}$ and ketamine $\mathrm{HCl}$ administration before deer lost the ability to stand (Mech et al. 1985). Our mean induction time in winter $(\overline{\mathrm{x}}=11.2$ minutes, $\mathrm{SE}=2.5$, range $=5.4-$ 24.3, $n=5$ ) was about double the median time of 6.2 minutes (range $=0.5-17.3$ ) reported by Jalanka and Roeken (1990) for 28 captive White-tailed Deer housed at the Helsinki Zoo, but similar to our summer mean time of 6.5 minutes $(\mathrm{SE}=0.8$, range $=6.2-7.5)$. In the Helsinki Zoo study, deer were given an average of $61 \mathrm{ug} / \mathrm{kg}(\mathrm{SD}=14$, median $=58$, range $=37-98)$ medetomidine $\mathrm{HCl}$ and a mean ketamine $\mathrm{HCl}$ dose of $1.6 \mathrm{mg} / \mathrm{kg}(\mathrm{SE}=0.3$, median $=1.5$, range $=1-2.3)$.

The time to walking after the IM injection of atipamezole $\mathrm{HCl}$ was similar to that for deer in other studies reversed with yohimbine $\mathrm{HCl}$, but was less

TABLE 1. Mean \pm SE $(\mathrm{N})$ vital signs of White-tailed Deer immobilized with medetomidine hydrochloride ( $\mathrm{HCl})$ and ketamine $\mathrm{HCl}$, and antagonized with atipamezole $\mathrm{HCl}$ during winter and summer 2001 in mid-Missouri for purposes of relocation (winter) and radio-collar attachment (summer). Adults were immobilized with $0.055 \mathrm{mg} / \mathrm{kg}$ medetomidine $\mathrm{HCl}$ and 2.5 $\mathrm{mg} / \mathrm{kg}$ ketamine $\mathrm{HCl}$ and subadults were immobilized with $0.06 \mathrm{mg} / \mathrm{kg}$ medetomidine $\mathrm{HCl}$ and $2.5 \mathrm{mg} / \mathrm{kg} \mathrm{ketamine} \mathrm{HCl}$. Adults were antagonized with $0.275 \mathrm{mg} / \mathrm{kg}$ of atipamezole $\mathrm{HCl}$ and subadults were antagonized with $0.03 \mathrm{mg} / \mathrm{kg}$ of atipamezole $\mathrm{HCl}$. We have not reported data where information was collected on $<2$ deer. Time 0 is the time of medetomidine $\mathrm{HCl}$ and ketamine $\mathrm{HCl}$ injection.

\begin{tabular}{|c|c|c|c|c|c|c|}
\hline \multirow[b]{2}{*}{$\begin{array}{l}\text { Time } \\
\text { (minutes) }\end{array}$} & \multicolumn{3}{|c|}{ Winter } & \multicolumn{3}{|c|}{ Summer } \\
\hline & $\begin{array}{l}\text { Respiration Rate } \\
\text { (breaths/minute) }\end{array}$ & $\begin{array}{c}\text { Pulse Rate } \\
\text { (beats/minute) }\end{array}$ & $\begin{array}{c}\text { Temperature } \\
\left({ }^{\circ} \mathrm{C}\right)\end{array}$ & $\begin{array}{l}\text { Respiration Rate } \\
\text { (breaths/minute) }\end{array}$ & $\begin{array}{c}\text { Pulse Rate } \\
\text { (beats/minute) }\end{array}$ & $\begin{array}{c}\text { Temperature } \\
\left({ }^{\circ} \mathrm{C}\right)\end{array}$ \\
\hline 0 & $27.2 \pm 2.1(5)$ & - & - & $23 \pm 1.4(4)$ & - & - \\
\hline 5 & $27.2 \pm 2.3(5)$ & - & - & $23 \pm 2.2(4)$ & - & - \\
\hline 10 & $28.8 \pm 2.9(5)$ & $\pm 3.6(4)$ & $41.1 \pm 0.5(2)$ & $31 \pm 2.4(4)$ & $98 \pm 2.0$ & $39.9 \pm 1.2(4)$ \\
\hline 15 & $29.6 \pm 3.2(5)$ & $88 \pm 4.3(4)$ & $40.9 \pm 0.8$ & $31 \pm 2.2$ & $101 \pm 1.9$ & $39.8 \pm 1.4(4)$ \\
\hline 20 & $31 \pm 3.2(4)$ & $94.7 \pm 3.6(3)$ & $40.6 \pm 1.2(3)$ & $30 \pm 2.6$ & $103 \pm 1.9$ & $39.8 \pm 1.4(4)$ \\
\hline 25 & $28 \pm 3.1(5)$ & $86 \pm 3.5(4)$ & $40.4 \pm 1.2(4)$ & $30 \pm 3.1(4)$ & $101 \pm 2.4(4)$ & $39.6 \pm 1.3(4)$ \\
\hline 30 & $29.3 \pm 3.6(4)$ & $\pm 5.6(2)$ & $39.3 \pm 1.9(2)$ & $32 \pm 2.9$ & $88 \pm 3.1$ & $39.3 \pm 1.2$ \\
\hline 35 & $24 \pm 2.4(2)$ & $\pm 1.2(2)$ & - & $24 \pm 0.0(2)$ & - & - \\
\hline 40 & - & - & - & $24 \pm 0.0$ & - & - \\
\hline 45 & $\pm 3.3(3)$ & - & - & - & - & - \\
\hline 50 & $\pm 3.3(3)$ & - & $40.1 \pm 1.2(2)$ & - & - & - \\
\hline
\end{tabular}


variable. An intravenous injection of yohimbine $\mathrm{HCl}$ following xylazine $\mathrm{HCl}$ and ketamine $\mathrm{HCl}$ immobilization resulted in an adult male walking in $1.5 \mathrm{~min}-$ utes ( $\mathrm{SE}=0.5, n=2$ immobilizations) to 26.5 minutes ( $\mathrm{SE}=11.5, n=4$ immobilizations $)$ for an adult female (Mech et al. 1985). For 22 White-tailed Deer (18 free-ranging captured using drop nets and 4 captive) immobilized with xylazine $\mathrm{HCl}$ and ketamine $\mathrm{HCl}$, an IM injection of yohimbine $\mathrm{HCl}$ produced a mean recovery time of 11.6 minutes $(\mathrm{SE}=2.3$ ) (Wallingford et al. 1996). Hsu and Shulaw (1984) used an IV injection of yohimbine $\mathrm{HCl}$ and reported a mean recovery time of 4.4 minutes ( $\mathrm{SD}=5.4$ minutes) for xylazine $\mathrm{HCl}$-immobilized deer.

With the exception of rectal temperature, the vital signs observed in this study were within the normal range of reported values for White-tailed Deer. Mautz and Fair (1980) reported pulse rates of a 46-kg adult White-tailed Deer female in July that was lying, standing/walking, and running at 65,74, and 106 beats per minute, respectively. Pulse rates observed in this study were similar to predicted walking pulse rates of Whitetailed Deer (Moen 1978: 722), yet higher than those rates reported by Jalanka and Roeken (1990: 267). Rectal temperatures of five deer were above $40^{\circ} \mathrm{C}$, a sign of hyperthermia (Kreeger 1996). Average rectal temperatures in our study in winter $\left(39.3^{\circ} \mathrm{C}\right.$ at 30 minutes, $\mathrm{SE}=1.9, n=2)$ and summer $\left(39.3^{\circ} \mathrm{C}\right.$ at 30 minutes, $\mathrm{SE}=1.2, n=4$ ) are similar to the maximum rectal temperatures reported by DelGuidice et al. (2001:1151) for White-tailed Deer captured by Clover trap and immobilized with xylazine $\mathrm{HCl}$ and ketamine $\mathrm{HCl}$ during the winter in Minnesota. Also in Minnesota, Rogers et al. (1987) reported rectal temperatures of two female free-ranging White-tailed Deer fawns in all seasons during various activities ranged between $38.2^{\circ}$ and $40.1^{\circ} \mathrm{C}$. Rectal temperatures of 3 adult male White-tailed Deer in Mississippi, averaged $39.3^{\circ} \mathrm{C}$ during late August and September and $38.6^{\circ} \mathrm{C}$ in early December (Demarais et al. 1986). As suggested by DelGiudice et al. (2001), corrective actions (i.e., packing snow around the animal) should be taken when immobilized animals become hyperthermic. Consequently, rectal temperatures should be monitored and protocols should be established to determine when corrective actions should begin (DelGiudice et al. 2001).

Both medetomidine $\mathrm{HCl}$ and ketamine $\mathrm{HCl}$ have wide safety margins, produce calm inductions in several artiodactyls, are safe for humans (Jalanka and Roeken 1990), and have not caused any apparent detrimental effects in pregnant females (Jalanka 1993). Few adverse side effects were noted by Jalanka and Roeken (1990) after 1240 immobilizations with medetomidine $\mathrm{HCl}$, ketamine $\mathrm{HCl}$, and antagonism with atipamezole $\mathrm{HCl}$. Worth noting, some ruminants became resedated between 30 and 240 minutes post-IV reversal with atipamezole $\mathrm{HCl}$ (Jalanka and Roeken 1990) and unre- markable ruminal tympany was common in ruminants prior to atipamezole $\mathrm{HCl}$ administration (Jalanka and Roeken 1990; Jalanka 1993).

A disadvantage of the medetomidine $\mathrm{HCl}$, ketamine $\mathrm{HCl}$, and atipamezole $\mathrm{HCl}$ combination is cost. In U.S. currency, cost to immobilize each adult deer was $\$ 34.72$ (\$32.76 for medetomidine $\mathrm{HCl}$ and \$1.96 for ketamine $\mathrm{HCl}$ ) and $\$ 18.85$ for each subadult deer ( $\$ 17.87$ for medetomidine $\mathrm{HCl}$ and $\$ 0.98$ for ketamine $\mathrm{HCl})$. Atipamezole $\mathrm{HCl}$ cost $\$ 33.22$ per adult deer and $\$ 18.14$ for each subadult deer. In contrast, Kilpatrick and Spohr (1999) reported a cost of $\$ 8.44 /$ deer for Telazol $^{\circledR}$ and xylazine $\mathrm{HCl}$ immoblized deer and \$6.34/ deer for ketamine $\mathrm{HCl}$ and xylazine $\mathrm{HCl}$ without lyophilizing costs. With lyophilizing, costs were $\$ 10.05$ / deer for $\mathrm{Telazol}^{\circledR}$ and xylazine $\mathrm{HCl}$ and $\$ 16.49$ for ketamine $\mathrm{HCl}$ and xylazine $\mathrm{HCl}$ (Kilpatrick and Spohr 1999). Consequently, use of medetomidine $\mathrm{HCl}$, ketamine $\mathrm{HCl}$, and atipamezole $\mathrm{HCl}$ may be cost-prohibitive in studies requiring immobilization of many animals. However, given the desirable properties discussed above, including rapid reversal that requires less manpower time, these desirable qualities may outweigh drug costs. Also, the ability to administer an antagonist IM may be advantageous in field studies (Wallingford et al. 1996). We recommend researchers investigate the utility of reversing the less costly and popular Telazol ${ }^{\circledR} /$ xylazine $\mathrm{HCl}$ and ketamine $\mathrm{HCl} /$ xylazine $\mathrm{HCl}$ combinations with an IM injection of atipamezole $\mathrm{HCl}$.

The combination of medetomidine $\mathrm{HCl}$, ketamine $\mathrm{HCl}$, and atipamezole $\mathrm{HCl}$ reported herein provided an effective level of anesthesia for Clover-trapped White-tailed Deer. We recommend the use of 0.055 $\mathrm{mg} / \mathrm{kg}$ medetomidine and $2.5 \mathrm{mg} / \mathrm{kg}$ ketamine $\mathrm{HCl}$ to immobilize adult Clover-trapped White-tailed Deer and $0.06 \mathrm{mg} / \mathrm{kg}$ medetomidine $\mathrm{HCl}$ and $2.5 \mathrm{mg} / \mathrm{kg}$ ketamine $\mathrm{HCl}$ for subadults. Furthermore, we recommend $0.275 \mathrm{mg} / \mathrm{kg}$ and $0.3 \mathrm{mg} / \mathrm{kg}$ of atipamezole, injected IM, to reverse this combination in adults and subadults, respectively.

\section{Acknowledgments}

We thank R. Houf, T. Mong, and numerous volunteers for their assistance in the field. Missouri Department of Conservation, Conservation Research Center, provided Clover traps. A University of Missouri Research Board grant, the University of Missouri, and the Missouri Department of Conservation supported this project.

\section{Literature Cited}

Arnemo, J. M. 1995. Immobilization of free-ranging moose (Alces alces) with medetomidine-ketamine and remobilization with atipamezole. Rangifer 15: 19-25.

Arnemo, J. M., T. Negard, and N. E. Soli. 1994. Chemical capture of free-ranging red deer (Cervus elaphus) with medetomidine-ketamine. Rangifer 14: 123-127. 
Bailey, T. J., C. A. Baker, P. K. Nicholls, and K. Wilson. 1995. Reversible anesthesia of the blue duiker (Cephalophus monticola) with medetomidine and ketamine. Journal of Zoo and Wildlife Medicine 26: 237-239.

Ballard, W. B., H. A. Whitlaw, D. L. Sabine, R. A. Jenkins, S. J. Young, and G. F. Forbes. 1998. White-tailed deer, Odocoileus virginianus, capture techniques in yarding and non-yarding populations in New Brunswick. Canadian Field-Naturalist 112: 254-261.

Bush, M., J. P. Raath, L. G. Phillips, and W. Lance. 2004. Immobilisation of impala (Aepyceros melampus) with a ketamine hydrochloride/medetomidine hydrochloride combination, and reversal with atipamezole hydrochloride. Journal of the South African Veterinary Association 75: 14-18.

Caulkett, N. A., P. H. Cribb, and J. C. Haigh. 2000. Comparative cardiopulmonary effects of carfentanil-xylazine and medetomidine-ketamine use for immobilization of mule deer and mule deer/white-tailed deer hybrids. Canadian Journal of Veterinary Research 64: 64-68.

Citino, S. B., M. Bush, D. Grobler, and W. Lance. 2001. Anaesthesia of roan antelope (Hippotragus equinus) with a combination of A3080, medetomidine and ketamine. Journal of the South African Veterinary Association 72: 29-32.

Dean, R., W. W. Hines, and D. C. Church. 1973. Immobilizing free-ranging and captive deer with phencyclidine hydrochloride. Journal of Wildlife Management 37: 82-86.

DelGiudice, G. D., B. A. Mangipane, B. A. Sampson, and C. O. Kochanny. 2001. Chemical immobilization, body temperature, and post-release mortality of white-tailed deer captured by Clover trap and net-gun. Wildlife Society Bulletin 29: 1147-1157.

Demarais, S., J. W. Foquay, and H. A. Jacobson. 1986. Seasonal rectal temperatures of white-tailed deer in Mississippi. Journal of Wildlife Management 50: 702-705.

Farley, G. H., T. A. Gavin, and T. S. Litwin. 1986. Immobilization of white-tailed deer with a ketamine and xylazine mixture: sex-specific differences. New York Fish and Game Journal 33: 28-33.

Fournier-Chambrillon, C., J. P. Chusseau, J. Dupuch, C. Maizeret, and P. Fournier. 2003. Immobilization of freeranging European mink (Mustela lutreola) and polecat (Mustela putorius) with medetomidine-ketamine and reversal by atipamezole. Journal of Wildlife Diseases 39: 393-399.

Gibson, D. F., P. F. Scanlon, and R. J. Warren. 1982. Xylazine hydrochloride for immobilizing captive white-tailed deer (Odocoileus virginianus). Zoo Biology 1: 311-322.

Grobler, D., M. Bush, D. Jessup, and W. Lance. 2001. Anaesthesia of gemsbok (Oryx gazella) with a combination of A3080, medetomidine and ketamine. Journal of the South African Veterinary Association 72: 81-83.

Haigh, J. C. 1982. Mammalian immobilizing drugs: their pharmacology and effects. Pages 46-62 in Chemical immobilization of North American wildlife. Edited by L. Nielsen, J. C. Haigh, and M. E. Fowler. Wisconsin Humane Society, Inc., Milwaukee, Wisconsin. 447 pages.

Haulena, M, F. M. D. Gulland, D. G. Calkins, and T. R. Spraker. 2000. Immobilization of California sea lions using medetomidine plus ketamine with and without isoflurane and reversal with atipamezole. Journal of Wildlife Diseases 36: 124-130.

Hsu, W. H., and W. P. Shulaw. 1984. Effect of yohimbine on xylazine-induced immobilization of white-tailed deer.
Journal of the American Veterinary Medical Association 185: 1301-1303.

Jacobsen, N. K., S. P. Armstrong, and A. N. Moen. 1976. Seasonal variation in succinylcholine immobilization of captive white-tailed deer. Journal of Wildlife Management 40: 437-453.

Jalanka, H. H. 1993. New alpha 2 -adrenoceptor agonists and antagonists. Pages 477-481 in Zoo and Wild Animal Medicine: Current Therapy 3. Edited by M. E. Fowler. W. B. Saunders Co., Philadelphia, Pennsylvania. 617 pages.

Jalanka, H. H., and B. O. Roeken. 1990. The use of medetomidine, medetomidine-ketamine combinations, and atipamezole in nondomestic mammals: A review. Journal of Zoo and Wildlife Medicine 21: 259-282.

Kilpatrick, H. J., and S. M. Spohr. 1999. Telazol-xylazine versus ketamine-xylazine: a field evaluation for immobilizing white-tailed deer. Wildlife Society Bulletin 27: $566-570$.

Klein, L. V., and A. M. Klide. 1989. Central alpha 2 -adrenergic and benzodiazepine agonists and their antagonists. Journal of Zoo and Wildlife Medicine 20: 138-153.

Kreeger, T. J. 1996. Handbook of wildlife chemical immobilization. International Wildlife Veterinary Services, Inc., Laramie, Wyoming. 342 pages.

Kreeger, T. J., G. D. DelGiudice, U. S. Seal, and P. D. Karns. 1986. Immobilization of white-tailed deer with xylazine hydrochloride and ketamine hydrochloride and antagonism by tolazoline hydrochloride. Journal of Wildlife Diseases 22: 407-412.

Mautz, W. W., and J. Fair. 1980. Energy expenditure and heart rate for activities of white-tailed deer. Journal of Wildlife Management 44: 333-342.

McCullough, D. R. 1975. Modification of the Clover Deer Trap. California Fish and Game 61: 242-244.

Mech, L. D., G. D. DelGiudice, P. D. Karns, and U. S. Seal. 1985. Yohimbine hydrochloride as an antagonist to xylazine hydrochloride-ketamine hydrochloride immobilization of white-tailed deer. Journal of Wildlife Diseases 21: 405-410.

Miller, M., M. Weber, D. Neiffer, B. Mangold, D. Fontenot, and M. Stetter. 2003. Anesthetic induction of captive tigers (Panthera tigris) using a medetomidine-ketamine combination. Journal of Zoo and Wildlife Medicine 34: 307-308.

Moen, A. N. 1978. Seasonal changes in heart rates, activity, metabolism, and forage intake of white-tailed deer. Journal of Wildlife Management 42: 715-738.

Nielsen, L. 1982. Electronic ground tracking of whitetailed deer chemically immobilized with a combination of etorphine and xylazine hydrochloride. Pages 165-174 in Chemical immobilization of North American wildlife. Edited by L. Nielsen, J. C. Haigh, and M. E. Fowler. Wisconsin Humane Society, Inc., Milwaukee, Wisconsin. 447 pages.

Presidente, P. J. A., J. H. Lumsden, D. R. Presnell, W. A. Rapley, and B. M. McGraw. 1973. Combination of etorphine and xylazine in captive white-tailed deer: II. Effects of hematologic, serum biochemical and blood gas values. Journal of Wildlife Diseases 9: 342-348.

Presnell, K. R., P. J. A. Presidente, and W. A. Rapley. 1973. Combination of etorphine and xylazine in captive whitetailed deer: I. Sedative and immobilization properties. Journal of Wildlife Diseases 9: 336-341. 
Rogers, L. L., A. N. Moen, and M. L. Shedd. 1987. Rectal temperatures of 2 free-ranging white-tailed deer fawns. Journal of Wildlife Management 51: 59-62.

Ryeng, K. A., J. M. Arnemo, and S. Larsen. 2001. Determination of optimal immobilizing doses of a medetomidine hydrochloride and ketamine hydrochloride combination in captive reindeer. American Journal of Veterinary Research 62: 119-126.

Ryeng, K. A., S. Larsen, and J. M. Arnemo. 2002. Medetomidine-ketamine in reindeer (Rangifer tarandus taran$d u s)$ : Effective immobilization by hand- and dart-administered injection. Journal of Zoo and Wildlife Medicine 33: 397-400.

Schultz, S. R., M. K. Johnson, and W. A. Forbes. 1992. Immobilization of captive white-tailed deer with mixtures of Telazol ${ }^{\circledR}$ and Rompun. Proceedings of the Annual Conference of Southeastern Association of Fish and Wildlife Agencies 46: 29-36.
Tsuruga, H., S. Masatsugu, T. Hiroshi, J. Kiyoe, and K. Koichi. 1999. Immobilization of sika deer with medetomidine and ketamine, and antagonism by atipamezole. Journal of Wildlife Diseases 35: 774-778.

Wallingford, B. D., R. A. Lancia, and E. C. Soutiere. 1996. Antagonism of xylazine in white-tailed deer with intramuscular injection of yohimbine. Journal of Wildlife Diseases 32: 399-402.

Wesson, J. A., P. F. Scanlon, and R. E. Mirarchi. 1974. Immobilization of white-tailed deer with succinylcholine chloride: success rate, reactions of deer and some physiological effects. Proceedings of the Annual Conference of the Southeastern Association of Game and Fish Commission 28: 500-506.

Received 2 March 2002

Accepted 3 October 2004 